Research Article

\title{
Vibration Characteristics of Heavy-Duty CNC Machine Tool-Foundation Systems
}

\author{
Yang Tian (D), ${ }^{1}$ Qilin Shu, ${ }^{1}$ Zhifeng Liu, ${ }^{2}$ and Yujie $\mathbf{J i}^{1}$ \\ ${ }^{1}$ School of Mechanical Engineering, Shenyang Ligong University, Liaoning, Shenyang 110159, China \\ ${ }^{2}$ College of Mechanical Engineering and Applied Electronics Technology, Beijing University of Technology, Beijing 100124, China
}

Correspondence should be addressed to Yang Tian; remlove@163.com

Received 18 May 2018; Accepted 27 August 2018; Published 25 September 2018

Academic Editor: Giorgio Dalpiaz

Copyright (c) 2018 Yang Tian et al. This is an open access article distributed under the Creative Commons Attribution License, which permits unrestricted use, distribution, and reproduction in any medium, provided the original work is properly cited.

Vibration characteristics of heavy CNC machine tools are directly affected by their foundations. To analyze vibrations of heavy CNC machine tools caused by internal and external loads, a system dynamics model of a rigid-flexible coupled heavy-duty CNC machine tool-foundation system was established based on the multibody transfer matrix method. Since joint surfaces can seriously affect the accuracy of system mechanics models, the substructure synthesis method was first used to establish a dynamic model of the joint surface. The frequency response function was then used to identify model parameters. Moreover, to improve the accuracy of parameter identification of the joint surface, a residual frequency compensation function was used to reconstruct the frequency response function. Finally, the multibody system model was implemented by combining surface elements. To verify the system dynamics model, an experimental model of the heavy-duty machine-foundation system was built, taking into consideration joint surface factors, and the theoretical model was validated by comparing theoretical, simulation, and experimental results. Using the theoretical model, the influence of different forms of concrete foundations, materials, and soil properties on the vibration characteristics of heavy-duty CNC machine tools was analyzed, thus providing a theoretical basis for optimizing and improving CNC machine tools.

\section{Introduction}

Vibrations generated by a machine's own excitations can seriously interfere with working conditions, particularly those of sensitive equipment. More importantly, relative vibration displacement can occur between a cutting tool and a machined part, which will directly affect the accuracy and surface quality of the machined part. Owing to interactions between the heavy-duty CNC machine tool and its foundation, there are significant differences in the calculation results obtained by directly using acceleration time histories as the inertial input and considering foundation. Analyzing the dynamic response of the machine tool structure alone is insufficient, and the influence of the concrete foundation on its dynamic characteristics should be considered.

To study the characteristics of the dynamic mechanicalfoundation system, it is necessary to establish an accurate system model. Previous research has been carried out on mechanical models of dynamic mechanical-foundation systems. Ghosh [1] used the three-dimensional finitedifference method to establish a dynamic mechanicalfoundation system model and studied the influence of a range of different artificial boundary conditions on the sensitivity of the static and dynamic characteristics of the system. When the artificial boundary value exceeds ten times the machine tool overall size, the sensitivity of the system significantly decreases. A three-dimensional finite-element model was proposed by Liu et al. [2] that considered a soilpower machine interaction system. Based on this model, the main factors influencing the dynamic response of the largescale machine tool-foundation were revealed. Aşık et al. [3] established an analytical solution for a bar and circular dynamic mechanical foundation model based on the variational principle and Hamiltonian principle of energy minimization. Cai et al. [4] conducted a series of analyses on the characteristics of foundation-foundation systems using cloud computing. Furthermore, Stanescu and Tabacu [5] considered the nonlinearity of soil and established a two-degree-of-freedom 
(DOF) machine-foundation model to study the stability of the equilibrium position.

The purpose of analyzing the characteristics of power machinery-foundation systems is to study their reliability, stability, and accuracy. However, system characteristics are often influenced by multifactor coupling. To reveal the influence of various factors, research has been conducted on the main factors affecting dynamic mechanical properties. Vivek and Ghosh [6] used the finite-element method to study the dynamic response of adjacent interacting mechanical foundations and analyzed the influence of distance between foundation profiles on the dynamic characteristics of the system. In another study, Štimac et al. [7] established a finite-element model of a turbogenerator-foundation system with the objectives of avoiding resonance caused by higher harmonics of the turbine and generator and optimizing the cross section of the foundation. Haldar and Sivakumar Babu [8] used a method that arranges spatial net stiffeners in the soil foundation to increase the natural frequency of the soil-foundation system, thereby avoiding resonance due to vibrations generated by the machine's rotations. Werner [9] deduced a vibration analysis model of the fundamental frequency of a machine-foundation system and demonstrated that the fundamental frequency of the system can be increased by increasing the contact area between the machine and foundation.

In each of the studies mentioned above, a dynamic mechanical-foundation system model based on theoretical and experimental analyses of the dynamic characteristics of the entire superstructure was established for various types of power machinery. However, the influence of joint surfaces was not considered in the system modeling process, and these studies lack sufficient validation of the system models.

In this paper, a mechanical model of a heavy-duty CNC machine tool-foundation system that considers the joint surfaces is established based on the multibody transfer matrix method. The theoretical model and simulations were validated by experiments performed in the laboratory on an equivalent scaled CNC machine tool-foundation system. Finally, the effects of different forms, materials, and reinforcement conditions of the concrete foundation, as well as different soil properties, on the dynamic characteristics of heavy-duty CNC machine tools were analyzed.

\section{Multibody System Theory Model}

The advantage of the transfer matrix method is that the stiffness matrix depends on the DOF of each substructure. Compared to the finite-element method, the total stiffness matrix can be effectively reduced. A multibody mechanical model was established according to the structural characteristics of the heavy-duty CNC machine tool and its foundations by considering the upper and lower structural subsystems. A dynamic equation can be established to describe the entire heavy-duty CNC machine-foundation system according to the state vector of the subsystem connection interface. A multibody dynamic model of the heavy-duty CNC machine tool-foundation system was established, as shown in Figure 1, in which the pillar, beam, connecting beam, bed body, and foundation were considered elastic elements due to their large-scale characteristics and the more rigid structures were considered rigid elements.

2.1. Joint Surface Element. Joint surfaces are responsible for $60 \%$ of the vibration problems of machine tools. For this reason, a transfer matrix at the joint surface needs to be established. State vectors of the input and output can be defined using the modal coordinate system as $Z_{\mathrm{I}}$ and $Z_{\mathrm{O}}$ [10].

According to the force balance equation, the joint surface transfer model can be obtained as follows:

$$
Z_{\mathrm{O}}=T^{K} Z_{\mathrm{I}}
$$

where $T^{K}$ is the transfer matrix of the bonding surface element. The transfer matrix of the transfer surface is a function of the state variable and excitation frequency, represented as follows:

$$
T^{K}=\left(\begin{array}{cc}
I_{6 \times 6} & k \\
O_{6 \times 6} & I_{6 \times 6}
\end{array}\right)
$$

where $k$ is a diagonal matrix incorporating both stiffness and damping. The diagonal matrix $k$ is given by

$$
k=\operatorname{diag}\left(\frac{-1}{k_{x}+j \omega c_{x}} \frac{-1}{k_{y}+j \omega c_{y}} \frac{-1}{k_{z}+j \omega c_{z}} \frac{-1}{k_{\alpha}+j \omega c_{\alpha}} \frac{-1}{k_{\beta}+j \omega c_{\beta}} \frac{-1}{k_{\gamma}+j \omega c_{\gamma}}\right),
$$

where $k_{x}, k_{y}$, and $k_{z}$ are the equivalent stiffness in $x-, y$-, and $z$-directions; $c_{x}, c_{y}$, and $c_{z}$ are the equivalent damping in $x$-, $y$-, and $z$-directions; $k_{\alpha}, k_{\beta}$, and $k_{\gamma}$ are the equivalent stiffness about the rotational displacement around the $x$-, $y$-, and $z$-directions; and $c_{\alpha}, c_{\beta}$, and $c_{\gamma}$ are the equivalent damping about the rotational displacement around the $x-, y$-, and $z$-directions.

2.2. Rigid Body Elements. During the modeling process, structural members of the heavy-duty CNC machine tool-foundation system with high stiffness values are regarded as rigid components. This greatly reduces the DOF of the substructure and also reduces the dimensionality of the system's stiffness matrix.

The rigid body space vibration transfer model can be expressed as follows:

$$
Z_{\mathrm{O}}=T^{R} Z_{\mathrm{I}}
$$

where $T^{R}$ is the rigid body vibration transfer matrix. The vibration transfer matrix is given by 


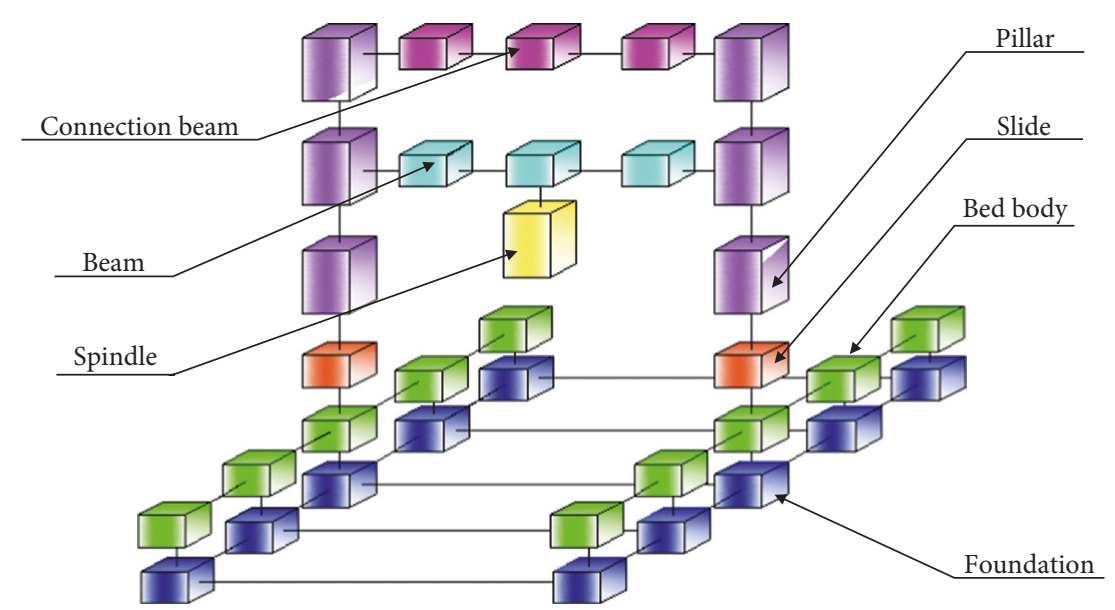

FIgURE 1: Multibody model of the heavy-duty CNC machine tool-foundation system.

$$
T^{R}=\left(\begin{array}{cccc}
I_{3 \times 3} & -P_{\mathrm{IO}} & O_{3 \times 3} & O_{3 \times 3} \\
O_{3 \times 3} & I_{3 \times 3} & O_{3 \times 3} & O_{3 \times 3} \\
m \omega^{2} I_{3 \times 3} & -m \omega^{2} P_{\mathrm{IC}} & I_{3 \times 3} & O_{3 \times 3} \\
m \omega^{2} P_{\mathrm{IC}} & -\omega^{2}\left(m P_{\mathrm{IO}} P_{\mathrm{IC}}+J_{\mathrm{I}}\right) & P_{\mathrm{IO}} & I_{3 \times 3}
\end{array}\right),
$$

where $P_{\mathrm{IO}}$ is the vector coordinate matrix of the output point position with respect to the input point position, $P_{\mathrm{IC}}$ is the matrix of the center of mass coordinates relative to the input point position vector, and $J_{\mathrm{I}}$ is the inertia matrix of the rigid body with respect to the input point.

2.3. Elastic Elements. An elastic body can be divided into $i$ sections, and according to the unit dynamic equation based on the principle governing system dynamics, modal coordinates are introduced. The unit input and unit output states can be substituted into the equation of motion to obtain the transfer matrix of the $i$-th unit. Combining $i$ units, the transfer model of the entire structure [11] can be defined as follows:

$$
Z_{\mathrm{O}}=T^{F} Z_{\mathrm{I}}
$$

where $T^{F}$ is the overall transfer matrix, $T^{F}=U_{n} U_{n-1}, \ldots, U_{2} U_{1}$, and $U_{i}$ is the transfer matrix of the $i$-th unit, given by

$U_{i}=\left[\begin{array}{cc}-\frac{\left(k_{11}^{i}-\omega^{2} m_{11}^{i}\right)}{\left(k_{12}^{i}-\omega^{2} m_{12}^{i}\right)} & I \\ \left(k_{21}^{i}-\omega^{2} m_{21}^{i}\right)+\frac{\left(k_{11}^{i}-\omega^{2} m_{11}^{i}\right)\left(k_{22}^{i}-\omega^{2} m_{22}^{i}\right)}{\left(k_{12}^{i}-\omega^{2} m_{12}^{i}\right)} & \left(k_{22}^{i}-\omega^{2} m_{22}^{i}\right)\end{array}\right]$,

where $m^{i}$ is the mass matrix of the $i$-th element and $k^{i}$ is the stiffness matrix of the $i$-th element.

2.4. Transfer Matrix of the Heavy-Duty CNC Machine ToolFoundation System. The system, China dynamics model of the heavy machine tool, is presented in Figure 2.
State vectors $Z_{1,2}, Z_{3,2}, Z_{4,3}, Z_{5,4}, Z_{6,5}, Z_{7,6}, Z_{8,6}, Z_{9,8}$, $Z_{10,9}, Z_{15,10}, Z_{11,15}, Z_{12,11}, Z_{13,12}, Z_{7,12}, Z_{16,15}, Z_{17,16}, Z_{18,17}$, $Z_{19,18}, Z_{20,19}, Z_{1}, Z_{14}$, and $Z_{20}$ can be defined. Elements 7,11 , and 13 are joint surface units which are input at both ends and output at one end. The state vectors can be defined by the following relations:

$$
\left\{\begin{array}{l}
Z_{I, 6}=E_{1} Z_{6,5}+E_{2} Z_{7,6}, \\
Z_{I, 15}=E_{3} Z_{10,15}+E_{4} Z_{16,15} \\
Z_{I, 12}=E_{5} Z_{12,11}+E_{4} Z_{13,12} .
\end{array}\right.
$$

The transfer matrices for each component are

$$
\left\{\begin{array}{l}
Z_{2,1}=T_{1} Z_{1}, \\
Z_{3,2}=T_{2} Z_{2,1}, \\
Z_{4,3}=T_{3} Z_{3,2}, \\
Z_{5,4}=T_{4} Z_{4,3}, \\
Z_{6,5}=T_{5} Z_{5,4}, \\
Z_{8,6}=T_{6} Z_{I, 6}, \\
Z_{9,8}=T_{7} Z_{8,6}, \\
Z_{10,9}=T_{8} Z_{9,8}, \\
Z_{15,10}=T_{9} Z_{10,9}, \\
Z_{11,15}=T_{10} Z_{I, 15}, \\
Z_{11,12}=T_{11} Z_{11,15}, \\
Z_{13,14}=T_{12} Z_{14}, \\
Z_{12,13}=T_{13} Z_{13,14}, \\
Z_{7,12}=T_{14} Z_{I, 12}, \\
Z_{6,7}=T_{15} Z_{7,12}, \\
Z_{19,20}=T_{16} Z_{20}, \\
Z_{18,19}=T_{17} Z_{19,20}, \\
Z_{17,18}=T_{18} Z_{18,19}, \\
Z_{16,17}=T_{19} Z_{17,18}, \\
Z_{15,16}=T_{20} Z_{16,17} .
\end{array}\right.
$$




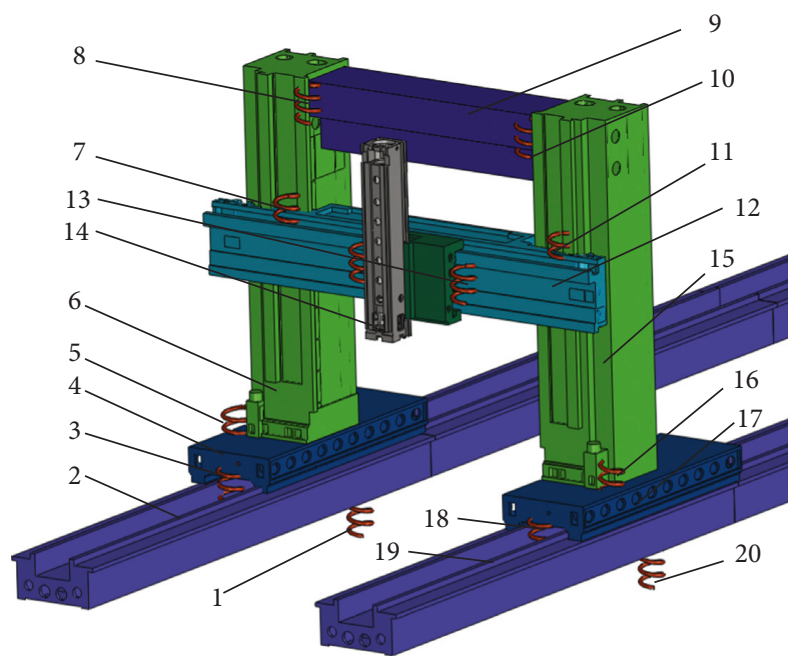

FIGURE 2: Dynamic model of the entire heavy machine tool. 1—bed-concrete joint surface; 2—bed body; 3-slide-bed joint surface; 4-slide; 5-pillar-slide joint surface; 6-pillar; 7-beam-left column joint surface; 8-left column-connection beam joint surface; 9-connection beam; 10 -right column-connection beam joint surface; 11-right column-beam connection surface; 12-beam; 13-carriage surface; 14-spindle; 15-pillar; 16-pillar-slide joint surface; 17—slide; 18—slide-bed joint surface; 19—bed body; 20—bed-concrete joint surface.

According to Equation (9), the following relations can be obtained:

$$
\left\{\begin{array}{l}
Z_{11,15}=T_{10}\left(E_{3} T_{9} T_{8} T_{7} Z_{8,6}+E_{4} T_{20} T_{19} T_{18} T_{17} T_{16} Z_{20}\right) \\
Z_{8,6}=T_{6}\left(E_{1} T_{5} T_{4} T_{3} T_{2} T_{1} Z_{1}+E_{2} T_{15} Z_{7,12}\right), \\
Z_{7,12}=T_{14}\left(E_{5} T_{11} Z_{11,15}+E_{6} T_{13} T_{12} Z_{14}\right) .
\end{array}\right.
$$

According to Equation (10),

$$
\begin{gathered}
E_{5} E_{3} E_{1} T_{14} T_{11-1} Z_{1}+\left(E_{5} E_{3} E_{2} T_{15-14} T_{11-6}-I\right) Z_{7,12} \\
+E_{6} T_{14-12} Z_{14}+E_{5} E_{4} T_{14} T_{11} T_{20-16} T_{10} Z_{20}=0 .
\end{gathered}
$$

The relationships at the joint surfaces of elements 7,11 , and 13 can be given by

$$
\left\{\begin{array}{l}
E_{7} T_{5} T_{4} T_{3} T_{2} T_{1} Z_{1}-E_{8} T_{15} Z_{7,12}=0, \\
E_{1} E_{9} T_{9-1} Z_{1}+E_{2} E_{9} T_{9-6} T_{15} Z_{7,12}-E_{10} T_{20-16} Z_{20}=0, \\
E_{1} E_{3} E_{11} T_{11-1} Z_{1}+E_{2} E_{3} E_{11} T_{11-6} T_{15} Z_{7,12} \\
\quad+E_{11} E_{4} T_{11-10} T_{20-16} Z_{20}-E_{12} T_{13-12} Z_{14}=0
\end{array}\right.
$$

Equations (11) and (12) can be written in the matrix form to obtain the total transfer matrix of the system, given by

$$
T_{\text {all }}^{s} Z_{\text {all }}^{s}=0,
$$

where $Z_{\mathrm{all}}^{s}$ is the overall state vector of the superstructure and $Z_{\text {all }}^{s}=\left[Z_{1}^{T}, Z_{7,12}^{T}, Z_{14}^{T}, Z_{20}^{T}\right]$. Thus, the overall transfer matrix of the superstructure is

$$
T_{\text {all }}^{\mathcal{S}}=\left[\begin{array}{cccc}
E_{5} E_{3} E_{1} T_{14} T_{11-1} & E_{5} E_{3} E_{2} T_{15-14} T_{11-6}-I & E_{6} T_{14-12} & E_{5} E_{4} T_{14} T_{11} T_{20-16} T_{10} \\
E_{7} T_{5-1} & -E_{8} T_{15} & 0 & 0 \\
E_{1} E_{9} T_{9-1} & E_{2} E_{9} T_{9-6} T_{15} & 0 & -E_{10} T_{20-16} \\
E_{1} E_{3} E_{11} T_{11-1} & E_{3} E_{2} E_{11} T_{11-6} T_{15} & -E_{12} T_{13-12} & E_{4} E_{11} T_{11-10} T_{20-16}
\end{array}\right] .
$$

Due to their large-scale characteristics, concrete foundations of heavy-duty gantry CNC machine tools must be considered as elastic bodies (Figure 3). Considering the concrete foundation as an elastic component, the position of the machine tool relative to the concrete foundation can be determined and dynamic characteristics of the machine tool at different positions on the foundation can be more accurately analyzed. Therefore, the finite-element transfer matrix of the concrete foundation can be expressed as follows:

$$
T_{\text {all }}^{x} Z_{\text {all }}^{x}=0 .
$$

The upper and lower structural boundary conditions are generally expressed in the following form:

$$
\left[\begin{array}{cc}
G^{s} & 0 \\
0 & G^{x}
\end{array}\right]\left\{\begin{array}{c}
Z_{\text {all }}^{s} \\
Z_{\text {all }}^{x}
\end{array}\right\}=0 .
$$

Therefore, the overall transfer matrix of the upper and lower structure is 


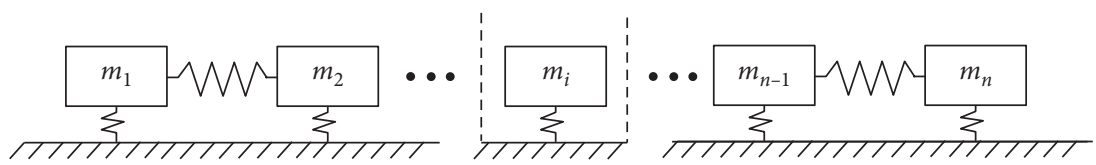

Figure 3: System dynamics model of the concrete foundation.

$$
\left[\begin{array}{cc}
T_{\text {all }}^{s} & 0 \\
0 & T_{\text {all }}^{x} \\
G^{s} & 0 \\
0 & G^{x}
\end{array}\right]\left\{\begin{array}{c}
Z_{\text {all }}^{s} \\
Z_{\text {all }}^{x}
\end{array}\right\}=0
$$

Then, Equation (17) can be simplified as follows:

$$
T_{\text {all }} Z_{\text {all }}=0 \text {. }
$$

\section{Parameter Identification of the Joint Surface}

The contact stiffness of a joint surface often contributes to the overall stiffness of a mechanical structure and, occasionally, may be the weakest part of the structure contributing to the overall stiffness. Therefore, to study the dynamic characteristics of mechanical structures, the contact stiffness of joint surfaces must be fully considered [12]. In this paper, metal-to-metal joints and the metal-to-concrete joints are analyzed. Due to the relatively low elasticity of concrete, as pressure acts across the large area of a concrete foundation, most of the protrusions on the concrete surface will break once a certain elastic limit is exceeded. This leads to uncertainty in the real contact area between the concrete and metal structure. Thus, an experimental identification method can be used to establish a unified parameter identification model for the metal-to-metal and concrete-toconcrete interfaces.

3.1. Dynamic Modeling of the Joint Surface. Heavy machine tools can be considered large fixed-weight structures owing to their size, and the load acts vertically on joint surfaces. As such, the influence of torsional freedom at the joint surface on the overall structure can be ignored [13]. An overall model of the substructure and interface can be established, as illustrated in Figure 4, and consists of three parts: substructure (1), substructure (2), and bolted joints.

Ignoring the mass of the bolted joints, the relationship between the frequency response function of the substructure and the displacement and external force can be expressed as follows:

$$
\begin{aligned}
& {\left[\begin{array}{l}
X_{a}^{(1)} \\
X_{p}^{(1)}
\end{array}\right]=\left[\begin{array}{ll}
H_{a a}^{(1)} & H_{a p}^{(1)} \\
H_{p a}^{(1)} & H_{p p}^{(1)}
\end{array}\right]\left[\begin{array}{c}
f_{a}^{(1)} \\
f_{p}+f_{p}^{(1)}
\end{array}\right],} \\
& {\left[\begin{array}{c}
X_{c}^{(2)} \\
X_{q}^{(2)}
\end{array}\right]=\left[\begin{array}{ll}
H_{c c}^{(2)} & H_{c q}^{(2)} \\
H_{q c}^{(2)} & H_{q q}^{(2)}
\end{array}\right]\left[\begin{array}{c}
f_{c}^{(2)} \\
f_{q}+f_{q}^{(2)}
\end{array}\right] .}
\end{aligned}
$$

The force balance condition at the joint surface of the substructure is

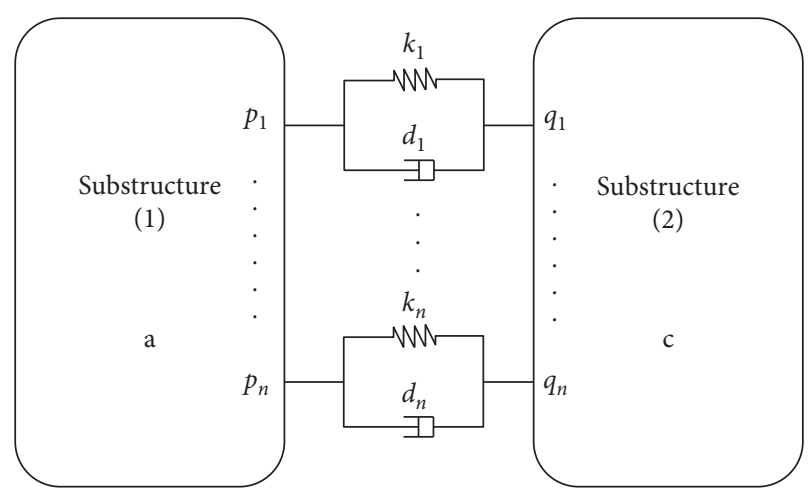

FIGURE 4: Typical structure of the heavy machine tool consisting of two substructures attached via bolted joints.

$$
f_{p}^{(1)}=-f_{q}^{(2)}
$$

As defined by the frequency response function, the displacement generated by internal forces at the bolted joint surface is

$X_{q}^{(2)}-X_{q}^{(1)}=H_{j} f_{p}^{(1)}=\left[\begin{array}{cccc}k_{1}+i \omega c_{1} & 0 & \cdots & 0 \\ 0 & k_{2}+i \omega c_{2} & \cdots & 0 \\ \vdots & \vdots & \ddots & \vdots \\ 0 & 0 & \cdots & k_{2}+i \omega c_{2}\end{array}\right]^{-1}$,

where $H_{j}=P_{j}^{-1}$.

According to Equations (19) and (22),

$$
\begin{aligned}
f_{p}^{(1)}= & \left(H_{p p}^{(1)}+H_{q q}^{(2)}+H_{j}\right)^{-1} \\
& \cdot\left(H_{q c}^{(2)} f_{c}^{(2)}+H_{q q}^{(2)} f_{q}-H_{p a}^{(1)} f_{a}^{(1)}-H_{p p}^{(1)} f_{p}\right),
\end{aligned}
$$

assuming $\alpha=\left(H_{p p}^{(1)}+H_{q q}^{(2)}+H_{j}\right)^{-1}$.

Based on Equations (19), (20), and (23), it follows that

$\left\{\begin{array}{l}X_{a}^{(1)}=\left(H_{a a}^{(1)}+H_{a p}^{(1)} \alpha H_{p a}^{(1)}\right) f_{a}^{(1)}+H_{a p}^{(1)} \alpha H_{q c}^{(2)} f_{c}^{(2)} \\ X_{c}^{(2)}=\left(H_{c c}^{(2)}-H_{c q}^{(2)} \alpha H_{q c}^{(2)}\right) f_{c}^{(2)}+H_{c q}^{(1)} \alpha H_{p a}^{(1)} f_{a}^{(1)}\end{array}\right.$

According to Equation (24),

$$
X^{(3)}=H^{(3)} f^{(3)} \text {, }
$$

where $X^{(3)}=\left[\begin{array}{c}X_{a}^{(1)} \\ X_{c}^{(2)}\end{array}\right]$ and $f^{(3)}=\left[\begin{array}{c}f_{a}^{(1)} \\ f_{c}^{(2)}\end{array}\right]$.

Then, Equation (25) can be modified to obtain

$$
\left\{\begin{array}{c}
X_{a}^{(1)} \\
X_{c}^{(2)}
\end{array}\right\}=\left[\begin{array}{ll}
H_{a a}^{(3)} & H_{a c}^{(3)} \\
H_{c a}^{(3)} & H_{c c}^{(3)}
\end{array}\right]\left\{\begin{array}{c}
f_{a}^{(1)} \\
f_{c}^{(2)}
\end{array}\right\} .
$$

Substituting Equation (24) into Equation (26), we obtain 


$$
\left[\begin{array}{cc}
H_{a a}^{(3)} & H_{a c}^{(3)} \\
H_{c a}^{(3)} & H_{c c}^{(3)}
\end{array}\right]=\left[\begin{array}{cc}
H_{a a}^{(1)}-H_{a p}^{(1)} \alpha H_{p a}^{(1)} & H_{a p}^{(1)} \alpha H_{q c}^{(2)} \\
H_{c q}^{(2)} \alpha H_{p a}^{(1)} & H_{c c}^{(2)}-H_{c q}^{(2)} \alpha H_{q c}^{(2)}
\end{array}\right]
$$

\subsection{Parameter Identification}

3.2.1. Identification Theory. From Equation (27), known as the identification equation, it can be seen that, by obtaining the frequency response function of the substructure and overall structure through testing, the equivalent dynamic parameters of the joint surface can be determined, thereby avoiding the need to measure the frequency response function of the integral structural joint. Thus, Equation (27) can be modified such that

$$
\begin{aligned}
A & =B \alpha C \\
A C^{-1} & =\left(B-A C^{-1}\left(H_{p p}^{(1)}+H_{q q}^{(2)}\right)\right) H_{j}^{-1} .
\end{aligned}
$$

Expressing Equation (29) as a linear system of equations, we obtain

$$
E(\omega)\left[I \quad i \frac{\omega}{\omega_{0}} I\right]\left[\begin{array}{l}
k \\
d
\end{array}\right]=g(\omega)
$$

Then, modifying Equation (30), we obtain

$$
E(\omega) z(\omega)=g(\omega)
$$

Finally, using the least squares method to solve Equation (31), we obtain

$$
\left[\begin{array}{l}
k \\
d
\end{array}\right]=\left[\sum_{i=1}^{n}\left[(E(\omega))^{T} E(\omega)\right]^{-1} \sum_{i=1}^{n}(E(\omega))^{T} g(\omega)\right] .
$$

3.2.2. Weighting. Since the value of the frequency response function varies significantly with changes in frequency, especially at the resonance frequency, identified joint surface parameters are almost completely controlled by resonance frequencies. In other words, when using the least squares method to solve the overdetermined equation, larger coefficients will have a greater influence on the solution. To make full use of the coefficient values, the effects of the coefficients can be averaged using a weight function method.

Simultaneously multiplying both sides of Equation (31) by the weighting matrix $W^{-1}$, we obtain

$$
W^{-1} E(\omega) z(\omega)=W^{-1} g(\omega),
$$

where $W=\operatorname{diag}\left(\begin{array}{llll}w_{1} & w_{2} & \cdots & w_{n}\end{array}\right)$, in which $w_{i}$ is the weighting factor, $w_{i}=\left(q_{i 1}^{2}+q_{i 2}^{2}+\cdots+q_{i n}^{2}\right)^{1 / 2}, \quad(i=1,2, \ldots$, $n)$, where $q_{\text {in }}$ is the parameter of matrix $E(\omega)$.

\subsection{Method for Obtaining Frequency Response Function.} Based on the identification method described in this paper, the frequency response function of each substructure, as well as the overall structure, must be acquired through testing and substituted into Equation (27). Then solving Equation (32), parameter values at the joint surfaces can be obtained. To identify the joint surface parameter, an experimental device was built. In this paper, the metal-concrete joint surface system is presented as an example. The test system is composed of the steel structural specimen, concrete specimen, strain bolt, force hammer, acceleration sensor, dynamic strain gauge, and signal acquisition and analysis system. Strain bolts were embedded into the concrete specimens at equidistant positions. The pretightening forces of bolts were obtained as strain values during the initial calibration. At the same time, the steel test piece was processed with a corresponding bolt hole, and a $1 \mathrm{~mm}$ high boss was machined around the bolt hole on the contact surface between the steel test piece and concrete to ensure full contact between the steel and concrete. The metal-concrete test system is shown in Figure 5.

\subsection{Frequency Response Function Reconstruction Method.} Due to modal truncation and clutter interference during the test process, some modal data are lost and the original experimental data will inevitably contain errors. To reduce these errors, a test frequency response function is reconstructed and the original experimental data are replaced with reconstructed data to improve the accuracy of parameter identification at the joint surface $[14,15]$.

The frequency response function of a typical mechanical joint is

$$
\begin{aligned}
H(\omega)= & \sum_{r=1}^{N} \frac{A_{r}}{\omega_{r}^{2}-\omega^{2}}=\sum_{r=1}^{m_{1}-1} \frac{A_{r}}{\omega_{r}^{2}-\omega^{2}}+\sum_{r=m_{1}}^{m_{2}} \frac{A_{r}}{\omega_{r}^{2}-\omega^{2}} \\
& +\sum_{r=m_{2}+1}^{N} \frac{A_{r}}{\omega_{r}^{2}-\omega^{2}},
\end{aligned}
$$

where $\omega_{r}$ denotes the $r$-th natural frequency and $A_{r}$ is the $r$-th modal constant. In Equation (34), the middle term, $\sum_{r=1}^{m_{1}-1} A_{r} /\left(\omega_{r}^{2}-\omega^{2}\right)$, is based on data obtained from testing, whereas the low-order term, $\sum_{r=m_{1}}^{m_{2}} A_{r} /\left(\omega_{r}^{2}-\omega^{2}\right)$, and highorder term, $\sum_{r=m_{2}+1}^{N} A_{r} /\left(\omega_{r}^{2}-\omega^{2}\right)$, are truncated by the test conditions and are, therefore, residual items that must be compensated.

A series of points on the frequency response function curve obtained during the experiment can be selected, denoted as $\left(\mu_{1}, H\left(\mu_{1}\right)\right),\left(\mu_{2}, H\left(\mu_{2}\right)\right), \ldots,\left(\mu_{n}, H\left(\mu_{n}\right)\right)$, where $\mu_{i}$ is the frequency. The interval $\left[\mu_{1}, \mu_{n}\right]$ is the actual desired frequency range. Substituting these data points into Equation (34) yields

$$
\left\{\begin{array}{c}
H\left(\mu_{1}\right) \\
\vdots \\
H\left(\mu_{n}\right)
\end{array}\right\}=\left[\begin{array}{ccc}
\left(\omega_{1}^{2}-\mu_{1}^{2}\right)^{-1} & \cdots & \left(\omega_{n}^{2}-\mu_{1}^{2}\right)^{-1} \\
\vdots & \ddots & \vdots \\
\left(\omega_{1}^{2}-\mu_{n}^{2}\right)^{-1} & \cdots & \left(\omega_{n}^{2}-\mu_{n}^{2}\right)^{-1}
\end{array}\right]\left\{\begin{array}{c}
A_{1} \\
\vdots \\
A_{n}
\end{array}\right\}
$$

where $\omega_{i}$ can be visually observed and extracted from the frequency response function curve; therefore, Equation (35) is an $n$-ary linear system of equations. The value of $A_{i}$ can be 


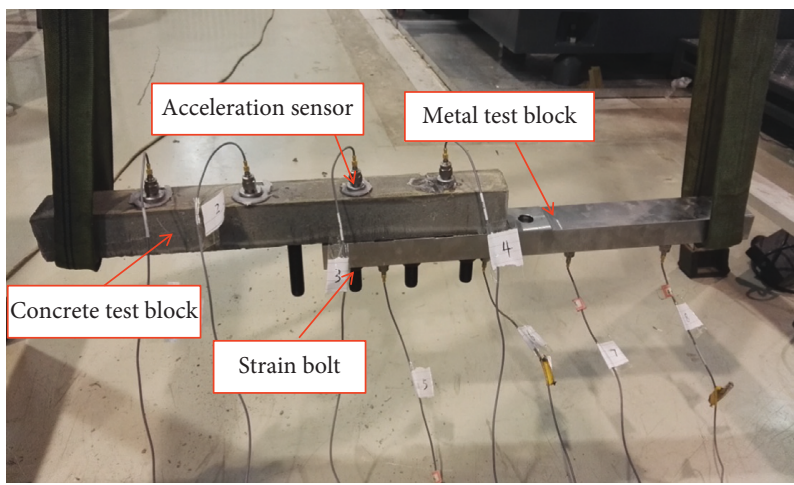

(a)

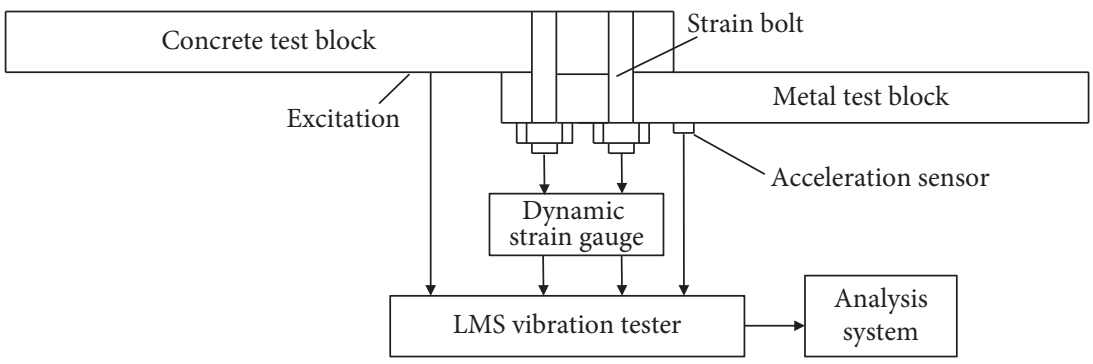

(b)

Figure 5: Basic experimental setup of the tool metal-concrete system. (a) Photograph of the test setup. (b) Schematic diagram of the test setup.

obtained by solving the system of equations, and this value can be substituted into Equation (34) to obtain the reconstructed frequency response function. The reconstructed frequency response function covers the $\left[\mu_{1}, \mu_{n}\right]$ frequency range, which is richer than the original frequency response function. This eliminates random signal interference to give a smoother frequency response curve. The reconstructed frequency response curve more clearly illustrates the response characteristics of major orders and eliminates clutter interference, which is useful for subsequent calculations.

\section{Dynamic Parameter Test}

4.1. Test Device. Field tests cannot be used to verify the effect of different-sized foundation, foundation forms, and soils on the dynamic characteristics of the system. Moreover, the characteristics of heavy-duty CNC machine tools make it impossible to carry out dynamic testing. Therefore, it is necessary to establish laboratory models of heavy-duty gantry CNC machine-foundations. The laboratory-based test device can solve a number of issues: wasted capital caused by the incompatibility of heavy-duty gantry $\mathrm{CNC}$ machine-foundation systems is reduced; the influence of joint surfaces between the structural members of the heavyduty gantry CNC machine tool, structural members, and concrete, and the concrete and soil are truly reflected; and studies relating to the influence of environmental factors on machining precision can be successfully carried out. In this paper, a test device that considers the influence of joint surfaces on a heavy-duty gantry CNC machine toolfoundation system is established.

4.1.1. Structure of Gantry, Concrete, and Foundation. The gantry system is composed of connecting beams, columns, supporting beams, and beds. Columns are used to machine four sets of holes connected to the crossbeams in the $z$ direction. Positioning the crossbeam through each set of holes achieves positioning relative to the four column positions. Thus, dynamic analysis of the crossbeam at four different positions can be carried out. The foundation is made of C40 concrete with an overall size of $1 \mathrm{~m} \times 0.5 \mathrm{~m}$. The test device is versatile and can be used to test different machine tools, foundations, and soils. In this paper, several types of concrete foundation blocks were prepared, including blocks of different sizes and varying reinforcement layers. Anchor bolts were arranged at the same position on the concrete foundation to allow the upper structure to be easily replaced.

4.1.2. Soil Box for Tests. The test device was constructed with a finite layer of soil. The size of the soil box is constrained by size of the laboratory, which should be large enough to still allow suitable excitations acting on the device to be produced. In designing the size of the soil box, pressure was taken into account, and the final dimensions were $2 \mathrm{~m} \times 1.5 \mathrm{~m} \times 1.5 \mathrm{~m}$. The inner side of the soil box was covered with a layer of rubber to prevent leakage of soil and provide a better lateral restraint. In addition, the lateral restraint prevents outward 


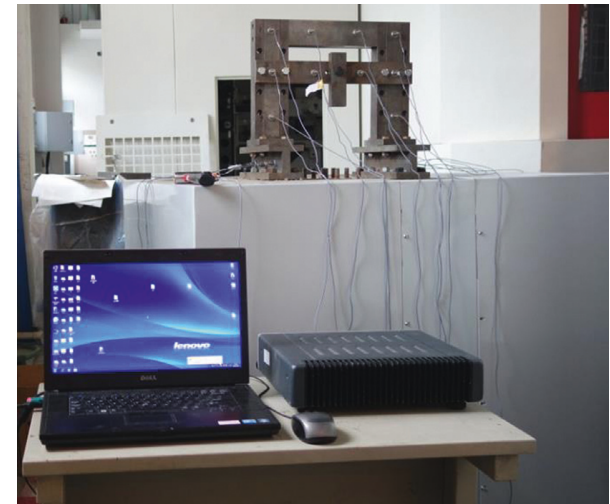

Figure 6: Dynamic analysis test system.

expansion of the soil and absorbs lateral boundary waves, thereby simulating a realistic soil boundary.

4.2. Test Analysis. The test system included a gantry structure-concrete foundation-soil system test stand, acceleration sensor, LMS test equipment and analysis software, and force hammer, as shown in Figure 6. For the experiments, three acceleration sensors were arranged on both sides of the base (an area of relatively high rigidity), four at the connection beams and crossbeams (relatively weak rigidity), three in the longitudinal direction of the column, and three in the $y$-direction of the bed. To reduce noise in the data, a force window was used for signal processing to ensure a low signal-to-noise ratio even in the presence of noise. By hammering in three directions above the gantry pillar, different formations were obtained.

A dynamic analysis system was used to perform modal experiments, and a comparison between the simulation and experimental model is shown in Figure 7.

From Figure 7, it can be seen that the simulation results align well with the experimental test results. Local modal shapes of the concrete foundation are only observed above $1600 \mathrm{~Hz}$ since the shape of the foundation used in experiments was monolithic; therefore, the modal frequency was relatively high. Moreover, since a scaled prototype model was used, the form matches that of the physical object; thus, the experiment provides preliminary preparation for field testing.

4.3. Comparison of Theory, Simulation, and Test Results. Considering Equation (18), the state vector of the zero elements in the matrix $Z_{\text {all }}$ is removed to obtain the matrix $\bar{Z}_{\text {all }}$, and the matrix $\bar{T}_{\text {all }}$ represents the structural parameters and natural frequency of the system. For any eigenvalue of the system, there must be a nonzero solution; therefore, the characteristic equation of the system is

$$
\left|\bar{T}_{\text {all }}\right|=0 .
$$

By solving Equation (36), the natural frequency of the system can be obtained. Moreover, by solving the transfer equation for each element, the state vector at each point, as well as the vibration mode of the system, can be obtained.
Theoretical values were also calculated, and a comparison of the theoretical, simulation, and experimental results is presented in Table 1.

Both the theoretical and simulation values are larger than the experimental values (Table 1), most likely due to the influence of the artificial boundary conditions of the soil. This effect can be seen by comparing the modal frequency values obtained from theory, simulation, and experiment, which are similar. A maximum error of $3.8 \%$ was obtained; therefore, the finite-element model and theoretical model were validated.

\section{Influence of Foundation Form on Overall Dynamic Characteristics}

To study the influence of the concrete foundation on the dynamic characteristics of a number of different heavy-duty CNC machine tools, a mechanics model based on the multibody transfer matrix system was used. First, according to the boundary conditions, the system transfer equation was solved and the boundary state vector at time $t_{i}$ was obtained. Then, the transfer equation of the component was used to obtain the state vector at each connection point of the system at time $t_{i}$. Incrementing by $i=i+1$ each time, the process is repeated until reaching the required time $T$. Finally, by changing the contour dimensions of the foundation, several properties were studied including the concrete foundation material, reinforcement conditions, and soil properties. Moreover, the displacement of the machine tool nose due to the impact load was determined. Thus, the effects of various influencing factors on machining accuracy were uncovered.

5.1. Influence of Foundation Contour Dimensions on Dynamic Response. As the contour dimensions of the foundation increase under the same impact, the displacement response at the tool nose becomes smaller, as shown in Figure 8, which suggests that contours of foundations significantly affect the dynamic response of heavy CNC machine tools. Increasing the contour size of the foundation also increases the mass of the foundation, and the joint surface between the foundation and soil becomes larger. This means the rigidity of the foundation boundary conditions increases, and the displacement of the tool nose decreases.

5.2. Influence of Concrete and Reinforcement. As the size of the concrete foundation increases, the maximum value of the dynamic response at the tool tip becomes smaller, as shown in Figure 9, and the response time is also reduced. This is because when the type of concrete changes, the modulus of elasticity of the concrete foundation also changes. If the elasticity increases, the increased rigidity of the concrete foundation also increases the stiffness at the metal-concrete joint surface. Changes in the type of concrete will therefore have a greater influence on the dynamic characteristics than changes in reinforcement. However, due to the relatively large amount of concrete in the foundation, the costs associated with the concrete are much larger than those associated with reinforcement. Therefore, the concrete 


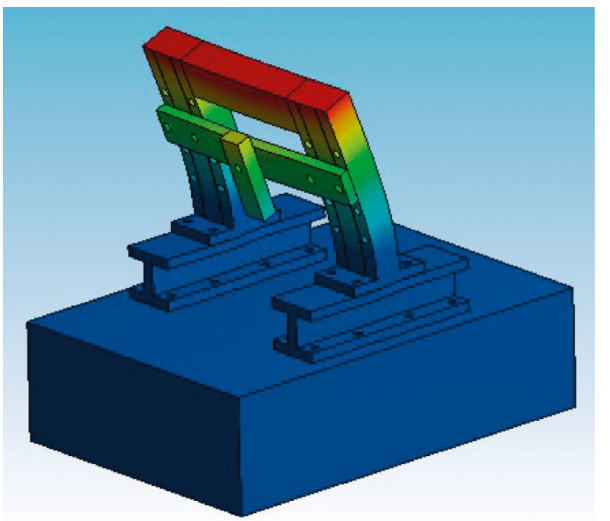

(a)

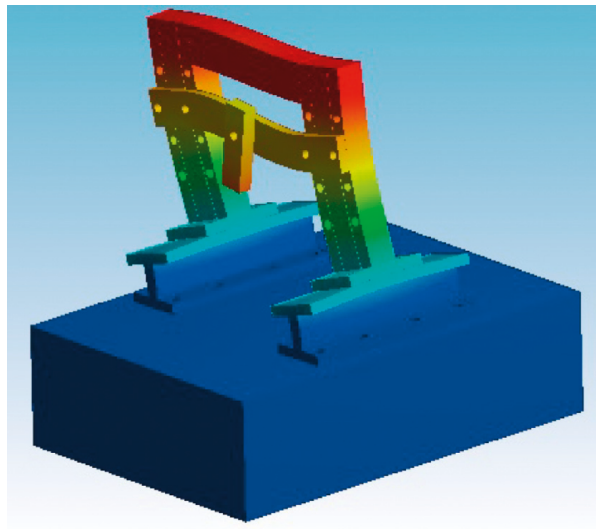

(c)

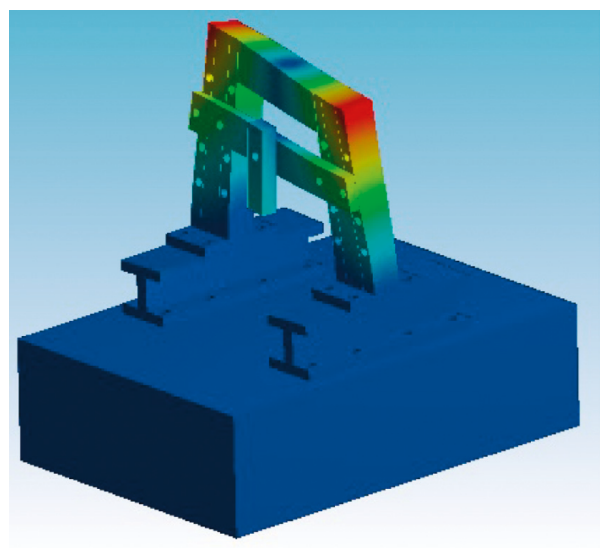

(e)

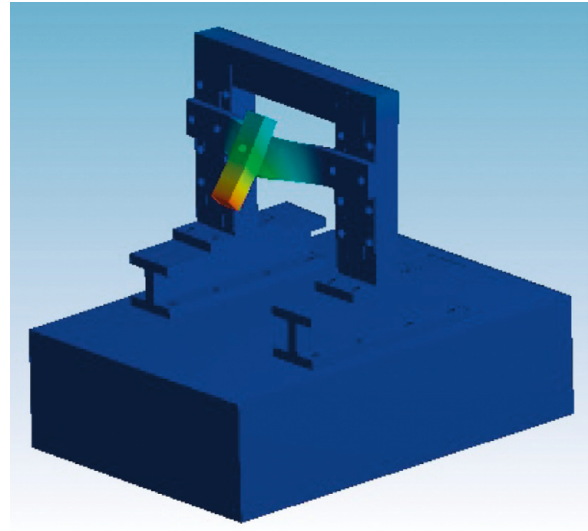

(g)

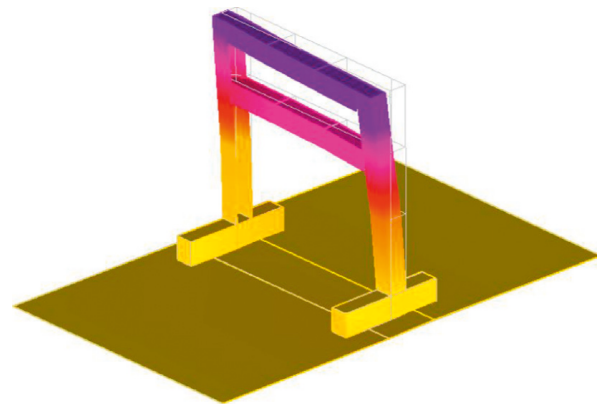

(b)

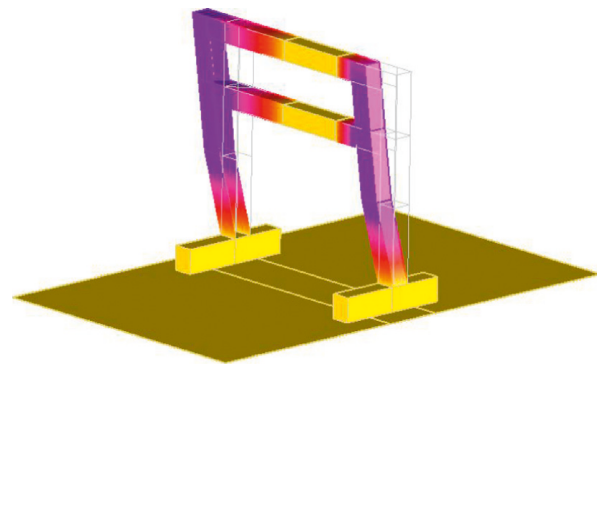

(d)

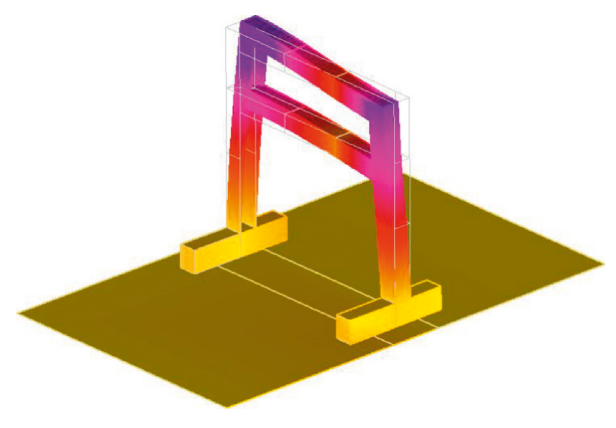

(f)

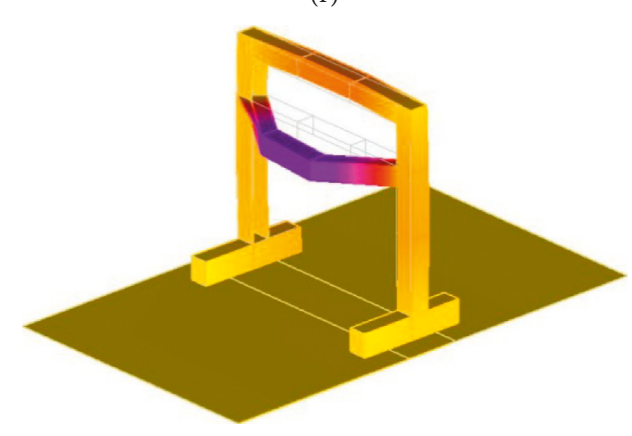

Figure 7: Continued. 


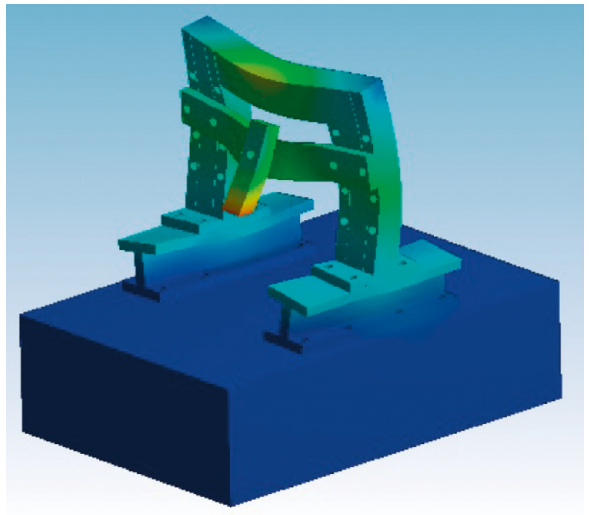

(i)

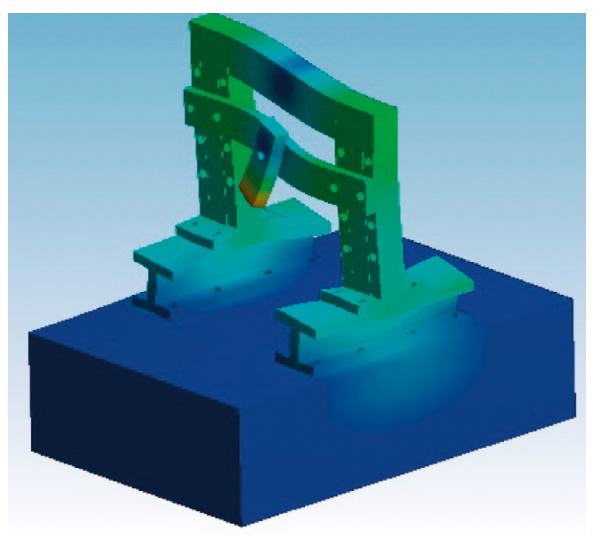

(k)

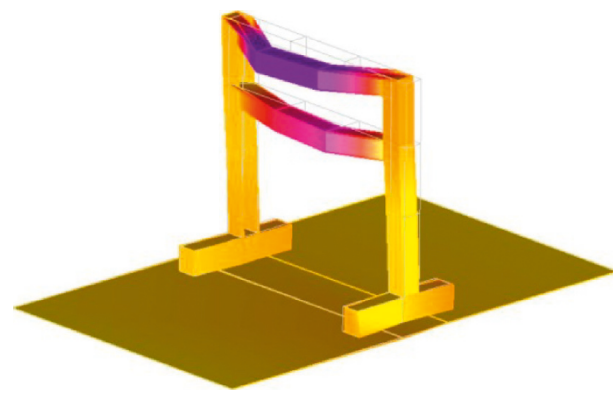

(j)

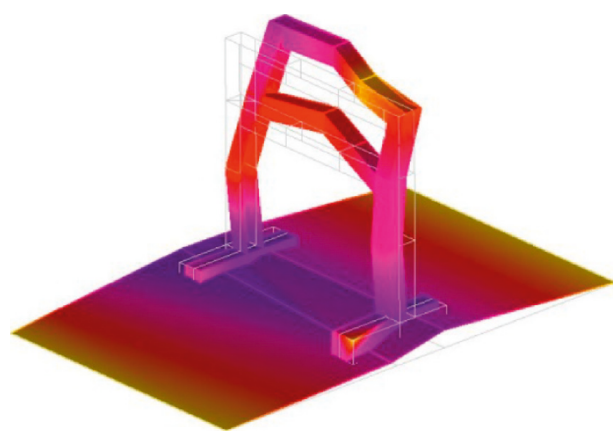

(1)

FIGURE 7: Comparison of simulation and experiment results: first-order natural frequency simulation (a) and laboratory test (b); secondorder natural frequency simulation (c) and laboratory test (d); third-order natural frequency simulation (e) and laboratory test (f); fourthorder natural frequency simulation (g) and laboratory test (h); fifth-order natural frequency simulation (i) and laboratory test (j); 12th order natural frequency simulation $(\mathrm{k})$ and laboratory test $(\mathrm{l})$.

TABLE 1: Comparison of theoretical, simulation, and experimental results.

\begin{tabular}{lcccccc}
\hline & $\begin{array}{c}\text { 1st } \\
\text { order } \\
(\mathrm{Hz})\end{array}$ & $\begin{array}{c}\text { 2nd } \\
\text { order } \\
(\mathrm{Hz})\end{array}$ & $\begin{array}{c}\text { 3rd } \\
\text { order } \\
(\mathrm{Hz})\end{array}$ & $\begin{array}{c}\text { 4th } \\
\text { order } \\
(\mathrm{Hz})\end{array}$ & $\begin{array}{c}\text { 5th } \\
\text { order } \\
(\mathrm{Hz})\end{array}$ & $\begin{array}{c}\text { 6th } \\
\text { order } \\
(\mathrm{Hz})\end{array}$ \\
\hline Theory & 195.28 & 238.46 & 400.41 & 649.16 & 937.25 & 1066.9 \\
Simulation & 191.17 & 236.29 & 395.67 & 641.68 & 934.43 & 1065.25 \\
Test & 188.12 & 231.98 & 394.21 & 640.43 & 931.34 & 1062.19 \\
\hline
\end{tabular}

model and reinforcement layers should be optimized during the design process to both improve the dynamic characteristics of the heavy machine tool-concrete foundation and reduce costs.

5.3. Influence of Soil Properties. As the soil becomes more rigid, the maximum dynamic response displacement at the tool tip decreases, as shown in Figure 10. However, the number of oscillations increases. This suggests that a harder soil can have an amplifying effect on the impact force, and soft ground can provide more shock absorption. For heavy-duty CNC machine tools, accuracy is important; therefore, the amplifying effects of harder soil should be

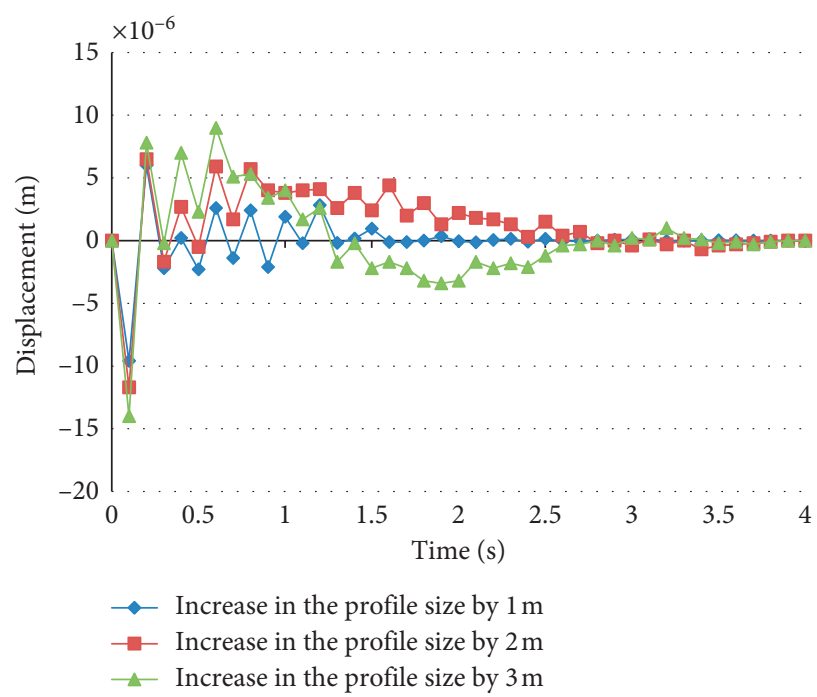

Figure 8: Influence of concrete foundation size on system dynamics.

avoided. Thus, selecting a suitable soil type is necessary since soil properties clearly play a key role in machining accuracy. 


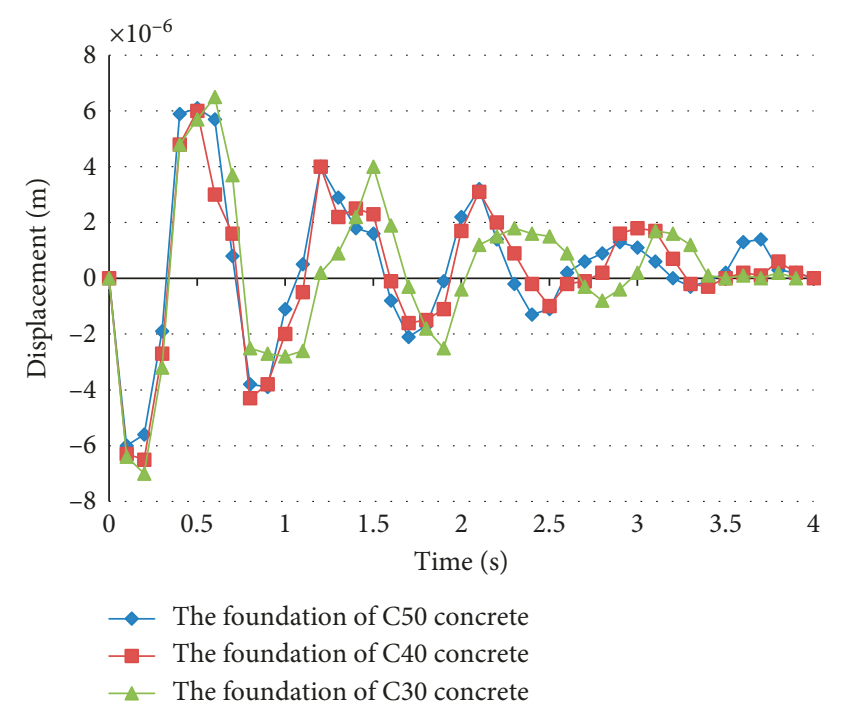

Figure 9: Effect of concrete type on system dynamic characteristics.

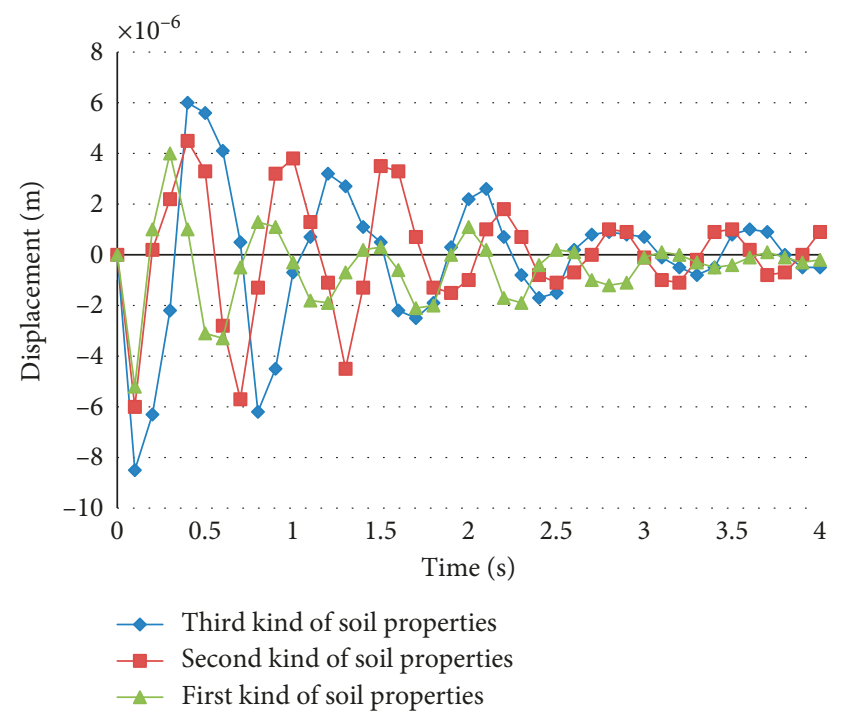

FIGURE 10: Influence of soil properties on system dynamics.

\section{Conclusions}

(1) Taking into account the influence of joint surfaces and soil properties at various locations within the machine tool-foundation system, a flexible coupled system made of steel was established based on the multibody transfer matrix method. Contour sizes of the foundation, as well as different concrete and soil properties, various mechanical models, and different forms of reinforcement were analyzed.

(2) In this paper, the substructure synthesis method was used to establish an overall dynamic model, and the frequency response function was applied to identify the parameters. The residual frequency compensation function was used to reconstruct the frequency response function, obtained via testing, thereby overcoming the errors associated with incomplete test data and clutter in the signal during the operation process to effectively improve the identification accuracy.

(3) To perform laboratory tests based on different machine tool structures, concrete foundations, and soil properties, a scaled model of the heavy-duty CNC machine tool-concrete foundation-soil system was built. Tests were performed, and the theoretical model and simulations were validated against the experimental results.

\section{Data Availability}

The data used to support the findings of this study are available from the corresponding author upon request.

\section{Conflicts of Interest}

The authors declare that they have no conflicts of interest.

\section{Acknowledgments}

This work was supported by the Natural Science Foundation of Liaoning Province, China (grant no. 20170540431), and Beijing Natural Science Foundation (grant no. 3162003).

\section{References}

[1] P. Ghosh, "FLAC based numerical studies on dynamic interference of two nearby embedded machine foundations," Geotechnical and Geological Engineering, vol. 30, no. 5, pp. 1161-1181, 2012.

[2] J. B. Liu, Z. Y. Wang, K. F. Zhang et al., "3D finite element analysis of large dynamic machine foundation considering soil-structure interaction," Engineering Mechanics, vol. 19, no. 3, pp. 34-35, 2002.

[3] M. Z. Aşık and C. V. G. Vallabhan, "A simplified model for the analysis of machine foundations on a nonsaturated, elastic and linear soil layer," Computers \& Structures, vol. 79, no. 31, pp. 2717-2726, 2001.

[4] L. Cai, Y. Tian, and Z. Liu, "Application of cloud computing to simulation of a heavy-duty machine tool," International Journal of Advanced Manufacturing Technology, vol. 84, no. 1-4, pp. 291-303, 2015.

[5] N. D. Stanescu and S. Tabacu, "Stability analysis for NeoHookean machine-tools foundations," Wseas Transactions on Applied and Theoretical Mechanics, vol. 5, no. 1, pp. 33-44, 2010.

[6] P Vivek and P. Ghosh, Dynamic Interaction of Two Nearby Machine Foundations on Homogeneous Soil, American Society of Civil Engineers, Reston, VA, USA, 2012.

[7] G Štimac, S Braut, and R Žigulić, "Structural optimization of turbine generator foundation with frequency constraint," Strojarstvo, vol. 53, pp. 389-398, 2011.

[8] S. Haldar and G. L. Sivakumar Babu, "Improvement of machine foundations using reinforcement," Proceedings of the Institution of Civil Engineers-Ground Improvement, vol. 162, no. 4, pp. 199-204, 2009. 
[9] U. Werner, "Derivation of a plane vibration model for electrical machines on soft machine foundations," Forschung im Ingenieurwesen, vol. 74, no. 4, pp. 185-205, 2010.

[10] X. T. Rui, B. He, B. Rong et al., "Discrete time transfer matrix method for dynamics of a multi-rigid-flexible-body system moving in plane," Proceedings of the Institution of Mechanical Engineers, Part K: Journal of Multi-body Dynamics, vol. 223, no. 1, pp. 23-42, 2009.

[11] X. T. Rui, Y. U. Hai-Long, H. E. Bin et al., "Finite element transfer matrix method of multibody system for naval gun vibration analysis," Acta Armamentarii, vol. 28, no. 9, pp. 1036-1040, 2007.

[12] S. Jiang, "Dynamic characteristic parameters of linear guideway joint with ball screw," Journal of Mechanical Engineering, vol. 46, no. 1, pp. 92-99, 2010.

[13] L. Li, L. Cai, T. Guo et al., "Identification of characteristic parameters of joints by substructure synthesis method," Journal of Vibration Measurement \& Diagnosis, vol. 31, no. 4, pp. 439-444, 2011.

[14] Z. Liu, X. Song, Y. Zhao et al., "Stiffness identification of spindle-toolholder joint based on finite difference technique and residual compensation theory," Advances in Mechanical Engineering, vol. 5, article 753631, 2013.

[15] Y. Zhao, X. Song, L. Cai et al., "Surface fractal topographybased contact stiffness determination of spindle-toolholder joint," Proceedings of the Institution of Mechanical Engineers, Part C: Journal of Mechanical Engineering Science, vol. 230, no. 4, pp. 1989-1996, 2015. 


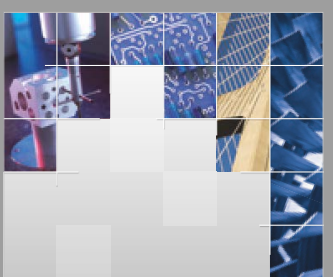

\section{Enfincering}
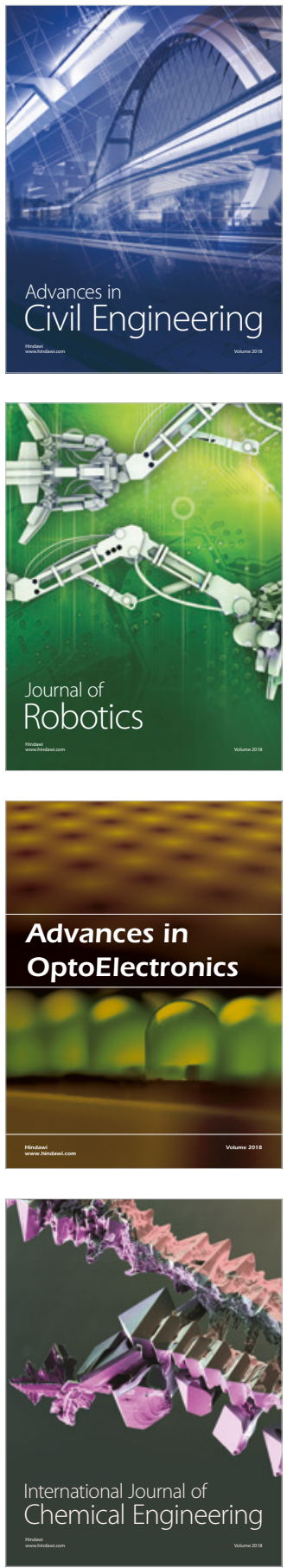

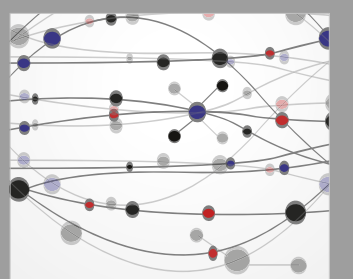

\section{Rotating \\ Machinery}

The Scientific World Journal

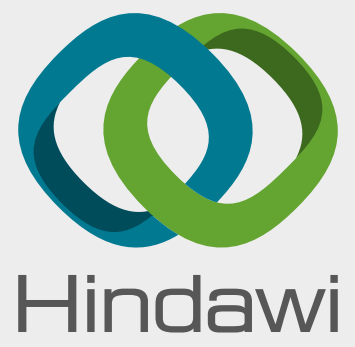

Submit your manuscripts at

www.hindawi.com
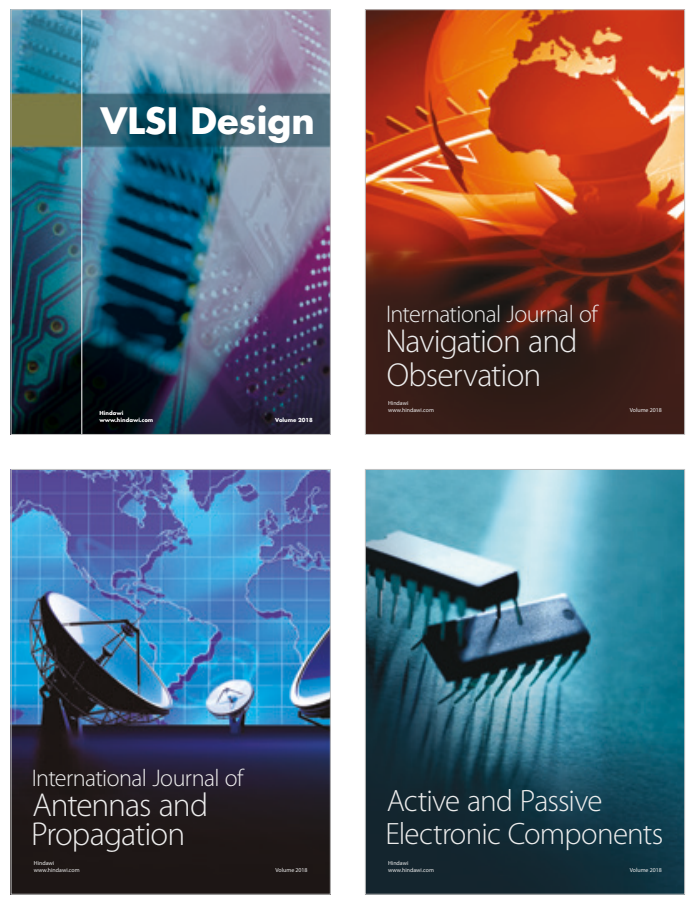
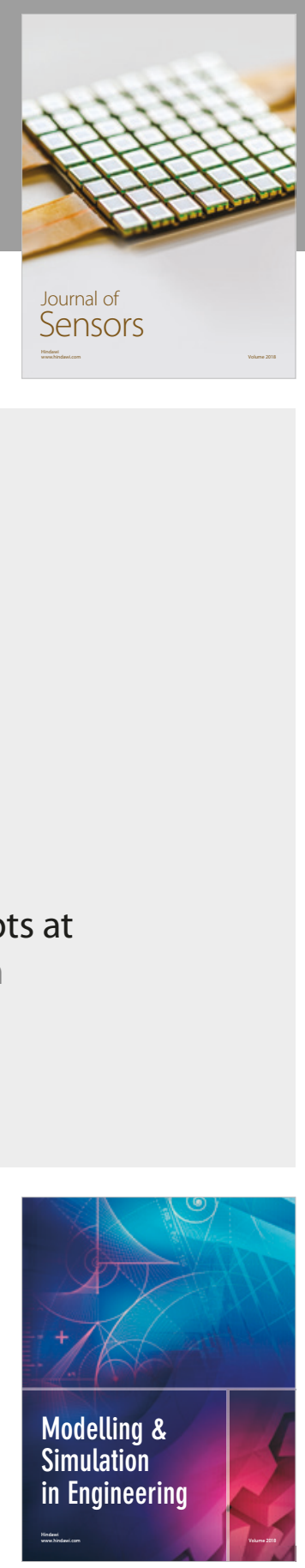

\section{Advances \\ Multimedia}
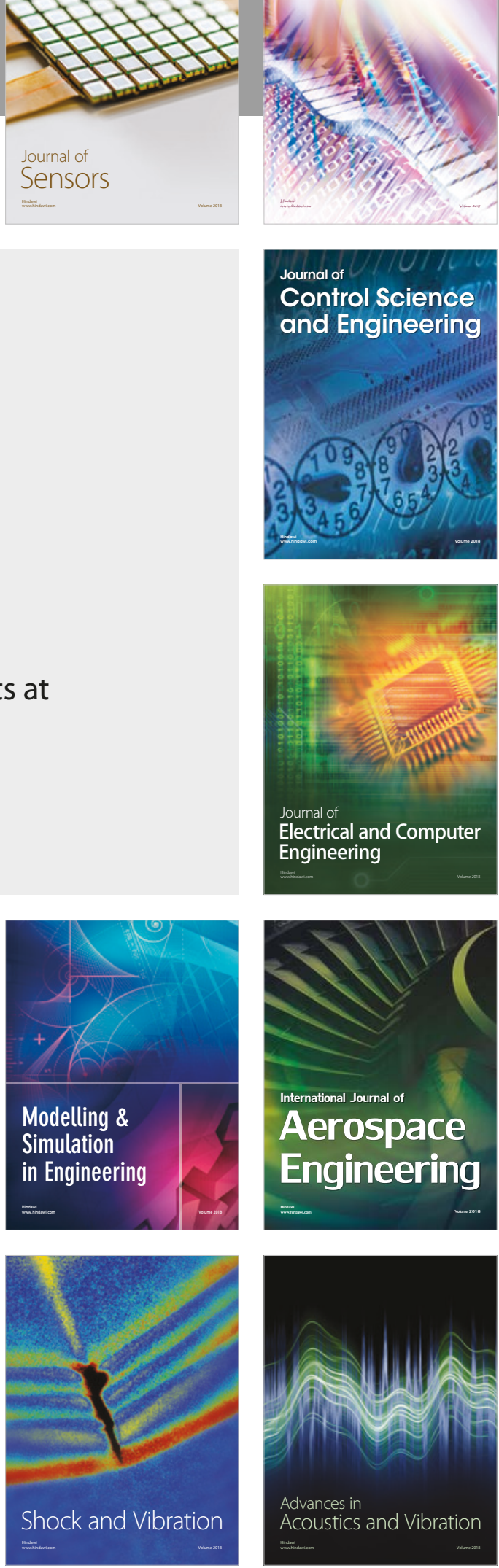